\title{
Vírus, viróides, fitoplasmas e espiroplasmas detectados em plantas ornamentais no período de 1992 a $2003^{1}$
}

\author{
MARIA AMÉLIA VAZ ALEXANDRE ${ }^{2,4}$, PATRÍCIA VAGUEIRO SEABRA ${ }^{2,4}$, ELIANA BORGES RIVAS ${ }^{2}$, \\ LÍGIA MARIA LEMBO DUARTE² e SILVIA REGINA GALLETI ${ }^{3}$
}

\begin{abstract}
RESUMO
No período de 1992 a 2003 foi investigada, visando diagnóstico, a presença de vírus, viróides, fitoplasmas e espiroplasmas em 167 gêneros de plantas ornamentais, pertencentes a 64 famílias. Para o diagnóstico e a identificação desses patógenos, foram realizados ensaios biológicos, serológicos e/ou moleculares, bem como observações ao microscópio eletrônico de transmissão. Tospovirus foram detectados em 104 amostras pertencentes a 15 gêneros, incluindo flores de corte, envasadas e folhagens; Potyviridae estavam presentes em 23 gêneros, dentre esses Hyppeastrum, Lilium, Gladiolus e Dieffenbachia infectados com Potyvirus; Cucumovirus (Cucumber mosaic virus) e Ilarvirus foram detectados em 14 e 5 gêneros, respectivamente; Tobamovirus e Potexvirus, que são de ocorrência freqüente no Brasil, infectaram $40,4 \%$ das orquídeas que representaram 29,3\% do total de amostras recebidas; outros 7 gêneros (Badnavirus, Carlavirus, Caulimovirus, Furovirus, Nepovirus, Tobravirus e Tymovirus) e duas famílias (Closteroviridae e Rhabdoviridae) de fitovírus foram também detectados. Nesse período, pelo menos três novas espécies de vírus foram descritas infectando crisântemo, petúnia e caládio. Viróide foi detectado em crisântemo, fitoplasma em lisiantos e espiroplasma em prímula.
\end{abstract}

Palavras-chave: Horticultura ornamental, Fitoviroses, Cucumovirus, Potexvirus, Potyviridae, Rhabdoviridae, Tobamovirus, Tospovirus

\begin{abstract}
Virus, viroid, phytoplasm and spiroplasm detected in ornamental plants from 1992 to 2003

At the Laboratório de Fitovirologia e Fisiopatologia (Instituto Biológico), a total of 167 genera of ornamental plants belonging to 64 families were investigated, from 1992 to 2003, for the presence of virus, viroid, phytoplasm and spiroplasm caused diseases. The diagnosis and identification of the viruses were carried out by means of biological, serological and molecular assays as well as electron transmission microscopy. Tospovirus were detected in 104 samples belonging to 15 genera including cut and potted flowers along with foliage plants; Potyviridae species were present in 23 genera, among which Hyppeastrum, Lilium, Gladiolus and Dieffenbachia were infected by Potyvirus; Cucumovirus (Cucumber mosaic virus) and Ilarvirus infected 14 and 5 genera, respectively; Tobamovirus and Potexvirus, which are the two most frequent viruses in Brazil, were found in $40.4 \%$ of the orchids which represented $29.3 \%$ of the ornamental plants analised; another 7 genera (Badnavirus, Carlavirus, Caulimovirus, Furovirus and Nepovirus, Tobravirus, Tymovirus) and two families (Closteroviridae and Rhabdoviridae) of plant viruses were also detected. In this period, at least three new virus species were described in chrysanthemum, petunia and caladium. Viroid was detected in chrysanthemum, phytoplasm in lisianthus and spiroplasm in primula.
\end{abstract}

Key words: Ornamental horticulture, plant viruses, Cucumovirus, Potexvirus, Potyviridae, Rhabdoviridae, Tobamovirus, Tospovirus

\footnotetext{
${ }^{1}$ Parcialmente financiado pela FAPESP.

${ }^{2}$ Laboratório de Fitovirologia e Fisiopatologia, Centro de Pesquisa e Desenvolvimento de Sanidade Vegetal, Instituto Biológico (IB). Av. Cons. Rodrigues Alves 1252, 04014-002, São Paulo, Brasil.

${ }^{3}$ Lab. de Microscopia Eletrônica. Centro de Pesquisa e Desenvolvimento de Sanidade Vegetal (IB).

${ }^{4}$ Bolsista do CNPq.
} 


\section{INTRODUÇÃO}

A horticultura ornamental apresentou um marcante crescimento nos últimos 40 anos, atingindo proporções substanciais e gerando grande interesse de produtores e investidores em todos os continentes (MALTER 1996). O setor de floricultura do Estado de São Paulo, em 2001, foi responsável por $70 \%$ do um bilhão de reais movimentados pelo mercado varejista brasileiro de plantas ornamentais; montante que se aproxima ao de outras culturas tradicionalmente relevantes como café, feijão e tomate para mesa. Ainda em 2001, o Estado de São Paulo exportou US\$ 9,9 milhões em plantas vivas e produtos de floricultura, representando $74 \%$ do total nacional (FRANCISCO et al. 2003).

O desenvolvimento da indústria da horticultura ornamental está baseado no suprimento de flores e plantas de alta qualidade, na tecnologia do transporte e no lançamento de produtos inovadores, sendo o controle de doenças, principalmente vírus e pragas, um pré-requisito para esse sucesso.

Visando atender a crescente demanda da horticultura ornamental no Estado de São Paulo, quanto ao diagnóstico de vírus, viróides, fitoplasmas e espiroplasmas, o laboratório de Fitovirologia e Fisiopatologia, do Centro de Pesquisa e Desenvolvimento de Sanidade Vegetal do Instituto Biológico (São Paulo), vem desenvolvendo pesquisas e ampliando a prestação de serviços nessa área.

Assim, este trabalho representa a compilação das informações obtidas; no período de 1992 a 2003, quanto à presença de tais agentes em 167 gêneros pertencentes a 64 famílias botânicas.

\section{MATERIAL E MÉTODOS}

\section{Transmissão mecânica}

Fragmentos de folhas, caules, pétalas, cormos ou bulbos foram triturados em presença de sulfito de sódio $0,5 \%$ ou tampão fosfato de sódio e potássio $0,01 \mathrm{M}, \mathrm{pH}$ 7,2 acrescido de $0,5 \%$ de sulfito de sódio. Os extratos foram inoculados em plantas indicadoras das famílias: Amaranthaceae (Gomphrena globosa), Balsaminaceae (Impatiens holstii), Chenopodiaceae (Chenopodium amaranticolor, C. murale, C. quinoa), Cucurbitaceae (Citrullus vulgaris, Cucumis sativus) e Solanaceae ( $D a$ tura metel, D. stramonium, Lycopersicon esculentum, Nicotiana benthamiana, $N$. clevelandii, $N$. debneyi, $N$. glutinosa, N. megalosiphon, N. rustica, N. tabacum 'Samsun', 'Samsun NN', 'TNN', 'White Burley' e Petunia hybrida).

\section{Transmissão por insetos vetores}

Insetos da espécie Myzus persicae (afídeo) foram empregados para a transmissão de alguns isolados do Cucumber mosaic virus (CMV) e algumas espécies de Potyvirus. Coleóptero Epicauta atomaria foi utilizado para ensaios de transmissão dos Tymovirus. As condições utilizadas para os experimentos de transmissão foram as descritas por DUARTE et al. (1994) e RIVAS et al. (2003).

\section{Serologia}

ELISA direto e indireto foram realizados a partir de extratos de tecidos infectados e sadios (controle), preparados na proporção de $1 \mathrm{~g}$ de tecido:10ml de tampão adequado. Os antissoros homólogos utilizados nos testes encontram-se relacionados na Tabela 1. Os métodos utilizados foram adaptados de DIJKSTRA \& DE JAGER (1998).

Tabela 1. Relação e procedência dos antissoros utilizados

\begin{tabular}{|l|c|}
\hline Antissoros & Procedência \\
\hline Bean yellow mosaic virus (BYMV) & 1 \\
\hline Chrysanthemum stem necrosis virus (CSNV) & 2 \\
\hline $\begin{array}{l}\text { Cucumber mosaic virus (CMV) } \\
\text { - isolado Commelina }\end{array}$ & 3 \\
\hline Cymbidium mosaic virus (CymMV) & 4 \\
\hline Cymbidium ringspot virus (CymRSV) & 4 \\
\hline Dasheen mosaic virus (DsMV) & 5 \\
\hline Eggplant mosaic virus (EMV) & 6 \\
\hline Groundnut mosaic virus (GRSV) & 2 \\
\hline Odontoglossum ringspot virus (ORSV) & 4 \\
\hline Pepper ringspot virus (PepRSV) & 3 \\
\hline Petunia vein banding mosaic (PetVBV) & 3 \\
\hline Tobacco mosaic virus (TMV) & 3 \\
\hline Tobacco streak virus (TSV) & 2 \\
\hline Tomato chlorotic spot virus (TCSV) & 3 \\
\hline Tomato mosaic virus (ToMV) & 2 \\
\hline Tomato spotted wilt virus (TSWV) & \\
\hline
\end{tabular}

${ }^{1}$ Embrapa Soja, Londrina/PR; ${ }^{2}$ Embrapa Hortaliças, Brasília/DF; ${ }^{3}$ Laboratório de Fitovirologia e Fisiopatologia, Instituto Biológico/SP; ${ }^{4} \mathrm{Agdia} / \mathrm{USA}$; ${ }^{5}$ Gainsville, Flórida, Estados Unidos; ${ }^{6}$ Braunschweig, Alemanha

\section{Microscopia eletrônica de transmissão}

A visualização da morfologia e das dimensões das partículas virais em extratos de tecidos sintomáticos ou não, foi realizada por meio da técnica de contrastação 
negativa. Para a observação de partículas virais in situ, assim como das alterações citoplasmáticas decorrentes da infecção viral, fragmentos de tecidos vegetais da espécie original e de algumas plantas experimentalmente inoculadas foram processados para obtenção de cortes ultrafinos (DUARTE et al., 1999). As preparações foram observadas em microscópio eletrônico de transmissão Philips EM 208.

\section{Extração de RNA viral}

O ácido nucléico viral foi extraído utilizando-se dois diferentes métodos: o descrito pelo fabricante do reagente "TRIzol ${ }^{\mathrm{TM} "}$ (Life Technologies) e o descrito por CHOMCZYNSKI \& SACCHI (1987), que utiliza isotiocianato de guanidina/fenol/clorofórmio. Em ambos os métodos foram empregados tecidos sintomáticos, previamente triturados em presença de nitrogênio líquido.

\section{RT-PCR}

A reação de transcrição reversa (RT) e a reação em cadeia pela polimerase (PCR) foram realizadas nas condições descritas por ALEXANDRE et al. (2000b) para Tobamovirus; DUARTE et al. (2001) para o CMV; GIBBS et al. (1998) para Potexvirus; GIBBS \& MACKENZIE (1997) para Potyviridae e RESENDE et al. (1996) para Tospovirus. Os produtos obtidos na PCR foram analisados em gel de agarose $2 \%$ e visualizados em um transiluminador (UV).

\section{Seqüenciamento}

Quando o objetivo foi seqüenciar parte do genoma viral, os fragmentos foram excisados do gel e purificados com CONCERT Rapid Gel Extraction System, de acordo com as recomendações do fabricante (GIBCO-BRL). A reação de seqüenciamento foi feita com o sistema "Big Dye ${ }^{\mathrm{TM}}$ Terminator - Cycle Sequencing Ready Reaction" (PE Applied Biosystems).

\section{RESULTADOS E DISCUSSÃO}

Com base nos dados obtidos nos testes de transmissão, sintomas em plantas hospedeiras, morfologia da partícula viral, alterações citopáticas, serologia e/ou RT-PCR, foram identificados 17 espécies de fitovírus, pertencentes a 13 gêneros.

Um dos fitovírus, comumente observados em ornamentais, foi o Cucumber mosaic virus (CMV) serogrupo I (Fig.1 A, B e C), tendo sido detectado, biológica e serologicamente, em 15 espécies botânicas:
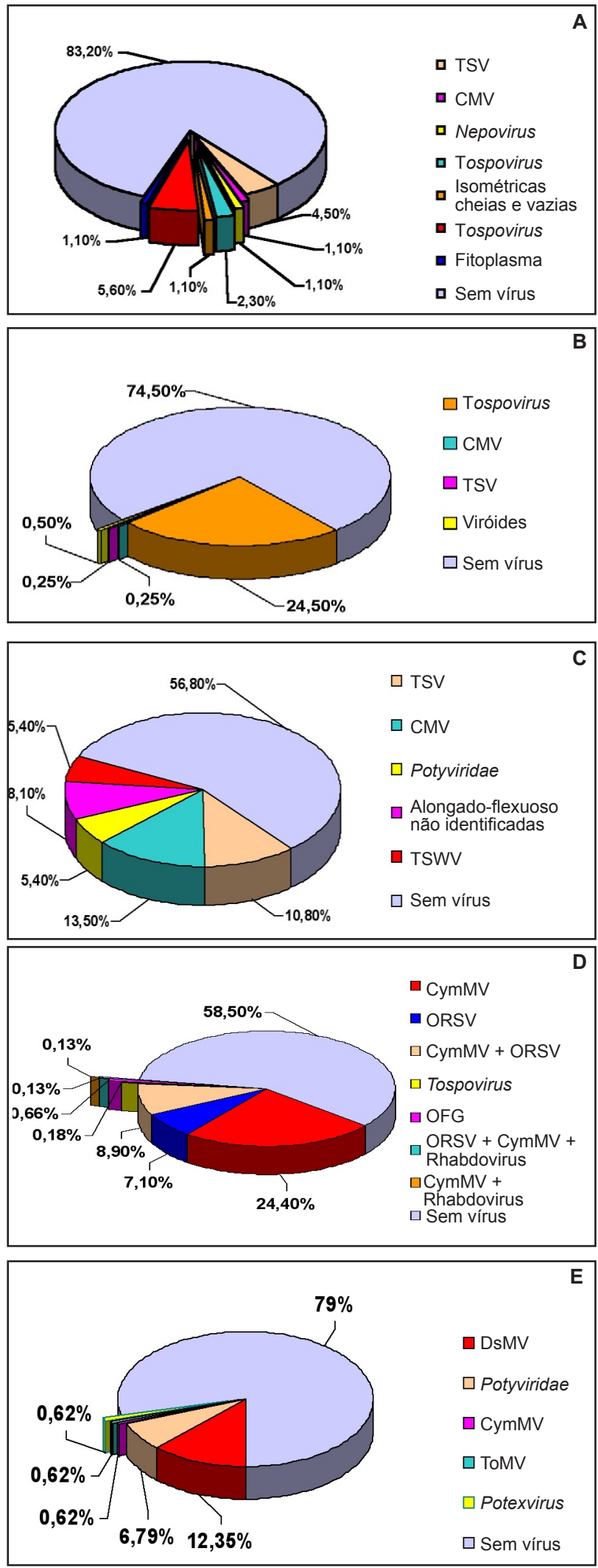

Figura 1. Distribuição dos vírus em plantas ornamentais. (A) Lisiantos, (B) Crisântemos, (C) Alstromérias, (D) Orquídeas, (E) Aráceas 
Aeschynanthus sp., Allamanda cathartica, Alstroemeria sp., Catharanthus roseus, Chrysanthemum morifolium, Commelina bengalensis, C. erecta, Eucharis grandiflora, Eustoma grandiflorum (Lisianthus russellianus), Gloxinia sylvatica, Hypocyrta nervosa (Nematanthus nervosus), Impatiens holstii, Lilium sp., Salvia splendens e Tradescantia elongata. Com o objetivo de realizar estudos de epidemiologia molecular, sete isolados foram também seqüenciados (números de acesso no "GenBank": AY377584, AY374327, AY374328, AY376840, AY380812, AY380533, AY380532), verificando-se que o CMV isolado de ornamentais não diferiu, molecularmente, daquele proveniente de hortaliças e frutíferas (DUARTE et al., 2003a). A pouca variabilidade genética entre os isolados de $\mathrm{CMV}$, possivelmente, é um dos fatores que contribuem para o sucesso evolutivo e para a ampla distribuição desse vírus entre as mais diversas hospedeiras (ROOSSINCK, 2002).

O gênero Cucumovirus compreende três espécies, CMV, Tomato aspermy virus e Peanut stunt virus, sendo o primeiro o único descrito no Brasil. SILBERSCHMIDT (1955) já havia relatado infecção natural por CMV em Asclepias curassavica, destacando a importância dessa e de outras espécies do gênero como hospedeiras naturais do vírus. COSTA (1983) relatou a ocorrência ocasional de CMV em Alstroemeria, alertando para a possibilidade de essa espécie atuar como fonte de disseminação desse vírus para outras espécies, especialmente porque, na natureza, o vetor (afídeo) é extremamente eficiente e polífago. Um aspecto ecológico a ser destacado é que, embora o CMV seja de fácil transmissão mecânica, muitas vezes, a presença do vetor é necessária para transmiti-lo para a espécie original. Esse fato ocorreu com o CMV, isolado de $I$. holstii, semelhantemente ao ocorrido com o isolado de Commelina descrito por DUARTE et al. (1994).

Quatro espécies de Tospovirus foram identificadas por meio de serologia e análise das seqüências do gene $\mathrm{N}:$ 1) Chrysanthemum stem necrotic virus (CSNV) em Callistephus chinensis, Chrysanthemum morifolium, Eustoma grandiflorum e Senecio cruentus; 2) Groundnut ringspot virus (GRSV) em Callistephus chinensis, E. grandiflorum e Hyppeastrum sp.; 3) Tomato chlorotic spot virus (TCSV) foi detectado em Bouvardia sp., Dieffenbachia amoena (RIVAS et al., 2002) e $E$. grandiflorum; 4. Tomato spotted wilt virus (TSWV) em Alstroemeria sp., C. morifolium, Dahlia sp., E. grandiflorum, Senecio cruentus e Sinningia speciosa. As seqüências obtidas estão disponíveis no "GenBank", sob os números: AY380780 (GRSV-Hyppeastrum), AY380813 (TCSV-Bouvardia) e AF454913 (TCSVDieffenbachia).

Em outras amostras de $S$. cruentus e $S$. speciosa, além de Exacum sp., Hedera sp., I. holstii, Petunia sp. e Oncidium flexuosum, partículas pleomórficas, típicas de Tospovirus, foram observadas ao microscópio eletrônico de transmissão, embora não tenha sido possível a identificação da espécie.

Com base nos dados obtidos, pôde-se verificar que os Tospovirus apresentam ampla distribuição entre as ornamentais (Fig.1 A, B, C, D e E), infectando tanto flores de corte como envasadas e folhagens, entretanto, apenas $E$. grandiflorum mostrou-se suscetível às quatro espécies detectadas (ALEXANDRE et al., 1999).

Com relação aos vetores de Tospovirus, a espécie de tripes predominante no Estado de São Paulo é Frankliniella schultzei (PAVAN et al. 1993), que transmite eficientemente TCSV, CSNV, GRSV e TSWV (WIJKAMP et al. 1995; NAGATA et al. 1999).

Dentre as espécies recebidas para exame, as orquídeas corresponderam a $29,3 \%$ das amostras, tendo sido observada a prevalência de duas espécies de vírus (Fig.1 D): 1) Cymbidium mosaic virus (CymMV) ocorrendo em Bifrenaria sp., Cattleya sp., Cymbidium sp., Dendrobium nobile, Epidendrum sp., Laelia purpurata, O. flexuosum, Phalaenopsis sp., Rodriguesia sp. e Wisticaria sp.; 2) Odontoglossum ringspot virus (ORSV) em Cattleya sp., Cymbidium sp., Laelia purpurata e Wisticaria sp. Cabe ressaltar que essas duas espécies de vírus, pertencentes aos gêneros Potexvirus (CymMV) e Tobamovirus (ORSV), ocorreram em infecções simples ou mistas (CymMV + ORSV). Um Rhabdoviridae, possivelmente o Orchid fleck virus (OFV), foi detectado em infecções simples em 5 amostras, Stanhopea sp., Cattleya sp., Miltonia sp. e duas de $O$. flexuosum, e em infecção mista em 2 amostras, Cymbidium sp. (CymMV + ORSV) e O. flexuosum (CymMV) (Fig.1 D). Além dessas três espécies de vírus, foi identificada, pela primeira vez, uma espécie de Tospovirus em Oncidium sp. (RIVAS et al., 2001a).

Conforme o esperado, CymMV e ORSV foram os vírus mais disseminados nas diferentes regiões produtoras do Brasil, fato que pode ser atribuído à estabilidade desses vírus, à propagação vegetativa e clonal das orquídeas, e, também, à sua fácil transmissão por tratos culturais (FREITAS, 1996; RIVAS et al., 1998b).

Dentre os Tobamovirus foram detectados e caracterizados biológica, serológica e molecularmente: 1) Tobacco mosaic virus (TMV) isolado de Petunia $\mathrm{x}$ hy- 
brida (número de acesso no GenBank: AY029262); 2) Tomato mosaic virus (ToMV) isolado de Dieffenbachia sp., Impatiens hawkeri (AY063743) e Hemerocallis sp.; 3) ORSV (AF515606) isolado de diversas espécies de orquídeas. Assim, relatou-se, pela primeira vez no Brasil, a ocorrência de TMV e ToMV em ornamentais (ALEXANDRE et al., 2000b, DUARTE et al., 2003), apesar de há muito essas espécies de Tobamovirus terem sido relatadas esporadicamente em hortaliças, causando danos severos. Em contraste à ocorrência freqüente de ORSV em orquídeas, a ocorrência do TMV e ToMV em ornamentais foi aleatória, sendo que em Hemerocallis tratava-se de material quarentenado. Em relação aos aspectos ecológicos, duas características são importantes para o sucesso dos Tobamovirus como patógenos: a sua alta estabilidade em condições adversas, ou seja, fora da planta, e sua transmissibilidade por contato e tratos culturais. Tais características podem ser facilmente observadas na relação ORSV-orquídea, tanto em orquidários como em culturas comerciais.

Além do CMV, Tobamovirus e Tospovirus, detectou-se, também, com grande freqüência, a presença de Potyviridae (Fig.1 C e D). Membros dessa família apresentam partículas alongado-flexuosas e induzem, caracteristicamente, a formação de inclusões citoplasmáticas cilíndricas em células infectadas. Assim, partículas virais foram observadas em 134 amostras de 15 gêneros botânicos, sendo que, em alguns casos, a identificação do vírus em gênero/espécie não pôde ser realizada (DUARTE et al., 1995). Por meio de testes serológicos foi possível identificar os Potyvirus: Dasheen mosaic virus (DsMV) e Bean yellow mosaic virus (BYMV), ambos transmitidos por afídeos. Desta forma, o DsMV, espécie que infecta exclusivamente aráceas, foi detectado em Dieffenbachia sp., Anthurium andraeanum, A. scherzerianum (RIVAS et al. 1997; 1998a,), Amorphophallus konjac, Caladium bicolor e Xanthosoma sp., enquanto que o BYMV foi detectado somente em amostras de Gladiolus sp. (ALEXANDRE et al., 2002) e Hyppeastrum sp.

A família Potyviridae representa cerca de $30 \%$ dos vírus que infectam plantas, os quais são cosmopolitas e, do ponto de vista econômico, os mais importantes por infectarem mais de 2000 espécies em 550 gêneros de plantas (BRUNT et al. 1997). Em plantas ornamentais, a infecção por Potyvirus é um dos fatores de restrição à sua comercialização, sendo os mais amplamente disseminados: o Turnip mosaic virus descrito em Anemone, Impatiens e Iris, e o BYMV em Eustoma, Freesia, Gladiolus, Iris, orquídeas e Dieffenbachia (COHEN
1995). Muitos Potyviridae causam quebra de coloração em flores e são especialmente importantes os transmitidos por sementes (SHUKLA et al., 1994). Assim, a identificação, pelo menos do gênero- de Potyviridae é fundamental para o manejo dessas culturas; por estar associada às informações sobre o vetor envolvido na transmissão/disseminação (afídeo, mosca-branca, ácaro ou fungo) e às suas relações ecológicas (SHUKLA et al., 1994). Com esse objetivo, e uma vez que não foram detectados por testes sorológicos e nem por transmissão para espécies indicadoras, a RT-PCR foi realizada para os Potyviridae presentes em Dieffenbachia sp., Eucharis grandiflora, Gladiolus sp., Hyppeastrum sp., I. holstii e Catharanthus roseus, com vistas a posterior seqüenciamento.

Apesar de os dados da literatura mostrarem que infecções naturais por Tymovirus são raras em plantas ornamentais, neste estudo duas espécies foram identificadas: 1) Eggplant mosaic virus (EMV) induzindo anéis concêntricos vermelhos em folhas de Peperomia obtusifolia (RIVAS et al., 2003); 2) Petunia vein-banding virus (PetVBV), uma nova espécie, causando faixa-das-nervuras em folhas de Petunia x hybrida (ALEXANDRE et al., 2000a). Das 21 espécies definitivas de Tymovirus, ocorrem, no Brasil, além das duas já mencionadas, o Passion fruit yellow mosaic virus (PFYMV) em maracujeiros. De um modo geral, as espécies de Tymovirus ocorrem, além das duas já mencionadas, esporadicamente, e não causam grandes perdas em culturas comerciais, talvez devido ao restrito círculo de hospedeiras e pelo fato de o vetor (coleóptero) não estar presente no campo durante todo o ciclo da cultura.

Das três espécies de Tobravirus aceitas pelo Comitê Internacional de Taxonomia Viral (ICTV), apenas Pepper ringspot virus (PepRSV), transmitida por nematóides, foi relatada no Brasil, ocorrendo tanto em hortaliças como em ornamentais. No período referido por este trabalho, PepRSV foi uma das espécies de fitovírus de ocorrência rara, sendo detectada apenas em E. grandiflorum de uma única propriedade agrícola (RIVAS et al., 2000b).

No Brasil, espécies do gênero Ilarvirus têm sido mais comumente reladas em plantas frutíferas, causando danos em frutos. Tobacco streak virus (TSV), por exemplo, foi há muito relatado em culturas de fumo e soja, porém, mais recentemente, não há relatos de sua ocorrência, pelo menos causando danos perceptíveis. Já em ornamentais, a ocorrência do TSV, embora esporádica, pôde ser constatada por meio de testes serológi- 
cos em Alstroemeria sp., C. morifolium e E. grandiflorum. O TSV isolado dessas três amostras induziu, em $N$. tabacum, sintomas típicos ${ }_{2}$ como riscas necróticas em folhas jovens e os denominados "folhas de couve" nas folhas acima das inoculadas.

Em algumas espécies ornamentais foram observadas infecções por vírus cujas espécies não puderam ser identificadas, mas que pertenciam aos seguintes gêneros e/ou famílias: 1) Badnavirus em Yucca elephantipes e Bougainvillea spectabilis; 2) Carlavirus isolado de Alstroemeria sp., Cassia macranthera e Primula sp.; 3) Caulimovirus em P. hybrida; 4) Closteroviridae observado em Lilium sp.; 5) Furovirus em samambaia; 6) Ilarvirus em Euphorbia splendens e Zinnia elegans; 7) Nepovirus em E. grandiflorum; 8) Potexvirus isolados de C. bicolor e Hylocereus undatus; 9) Potyviridae detectado em Alstroemeria sp., Anturium andraeanum, Bupleurum sp., Catharanthus roseus, Coreopsis sp., Dieffenbachia amoena, Dieffenbachia sp., Eucharis grandiflora, Gladiolus sp., Gypsophila sp., Hyppeastrum sp., I. holstii, Lilium longiflorum, Verbena sp. e Xanthosoma sp.; 10) Rhabdoviridae em Kalanchöe blossfeldiana; 11) Tobamovirus em Moraea sp.; 12) Tobravirus em Primula sp.; 13) Tospovirus em Exacum sp., Hedera sp., I. holstii, Senecio cruentus, P. hybrida, Oncidium sp. e Sinningia speciosa; 14) Tymovirus isolado de I. holstii.

Dentre os vírus que não puderam ser identifica$\operatorname{dos}_{2}$ havia aqueles com partículas isométricas, como os observados em Ajuga reptans, Chrysanthemum morifolium, Catharantus roseus, I. holstii, Lilium sp., Maranta sp., P. hybrida, Saintpaulia ionantha e Peperomia sp. Vírus com morfologia isométrica, mas com partículas cheias e vazias, foram observados em Viola tricolor, E. grandiflorum e C. roseus. Partículas alongado-flexuosas foram encontradas em I. holstii e Lilium sp. Vírus com morfologia baciliforme foram detectados em Dracaena surculosa e Hydrangea macrophylla.

Uma presença constante nas plantas ornamentais estudadas, como já mencionado em literatura internacional, foi a infecção mista, ou seja, aquela envolvendo mais de uma espécie de fitovírus em uma única planta hospedeira. Assim, pode-se constatar em Callistephus sp., C. morifolium, E. grandiflorum e $S$. cruentus infecções simultâneas por diferentes espécies de Tospovirus (ALEXANDRE et al. 1996, 1999); em O. flexuosum infecção por CymMV e OFV; em Cymbidium infecção por OFV + CymMV + ORSV; em P. hybrida a presença de Caulimovirus e PetVBV; em C. bicolor infecção por DsMV e Potexvirus; em Amaryllis sp. infecção por BYMV e vírus isométrico não identificado; em Alstroemeria sp. infecções por CMV + TSV, TSV + Tospovirus, além de CMV + Potyviridae; em D. amoena com TCSV e Potyviridae; em E. grandiflora infecção por CMV + Potyviridae; em I. holstii infecção por Tospovirus e Potyviridae; e em Lilium sp. a presença de CMV + Potyviridae, em Crassulaceae infecção por Rhabdoviridae e Potyviridae. Em Ficus rostrata e em outra amostra de Lilium sp. foram detectados vírus com morfologias alongado-flexuosa e isométrica.

Além de vírus, outros patógenos também foram detectados. Em crisântemo, apresentando nanismo, detectou-se, por hibridização, o Chrysanthemum stunt viroid. Em lisiantos com superbrotamento observou-se, por microscopia eletrônica, a presença no floema de corpúsculos pleomórficos típicos de infecção por fitoplasma e estruturas helicoidais, semelhantes à espiroplasma, em células do floema de prímula com amarelecimento.

Cabe ressaltar que, embora muitas espécies apresentassem sintomas semelhantes aos induzidos por vírus, partículas virais e alterações ultra-estruturais típicas de infecções virais não puderam ser observadas e, tampouco, houve transmissão mecânica para espécies indicadoras. Nessa categoria pode-se relacionar as seguintes espécies: Alcea rosea, Ananas sp., Anthurium andraeanum, Antirrhinum sp., Asparagus asparagoides, Begonia sp., Bomarea sp., Bromelia sp., Calathea sp., Canna sp., Celosia sp., Clerodendron thomsonae, Colocasia sp., Commelina sp., Cordyline sp., Cycas sp., Dianthus caryophyllus, Duranta repens, Eustoma grandiflorum, Evolvulus glomeratus, Fuchsia sp., Gerbera jamesoni, Grevillea sp., Guzmania sp., Hybiscus sp., Ixora sp., Jasminum sp., Ligustrum sp., Limonium sp., Lithrea sp., Malvaviscus arboreus, Mirabilis jalapa, Mandinella sp., Moluccella lanata, Laelia sp., Oxalis vulcanicola, palmeiras, Pelargonium sp., Peperomia scandens, Philodendron sp., Phoenix sp., Pilea microphylla, Platycerium bifurcatum, Plumeria sp., Portulaca grandiflora, Ranunculus sp., Rhododendron sp., Rosa sp., Sanchezia sp., Schefflera sp., Schlumbergera truncata, Scindapsus aureus, Solidago sp., Solanum sp., Spathiphyllum sp., Syngonium sp., Tabebuia sp., Tagetes erecta, Tradescantia sp., Tropaeolum majus, Vriesia sp., Xanthosoma sp. e Zelkova serrata.

A partir de 2000, atendendo à demanda do mercado de plantas ornamentais, novas variedades e espécies foram importadas. Assim, sementes, bulbos ou plântulas de Adiantum raddianum (6 variedades), Antirrhinum 
majus (4 variedades), Anthurium andraeanum, (16 variedades), A. scherzerianum (9 variedades), Begonia sp. (16 variedades), Calendula sp., Callistephus chinensis (31 variedades), Catharanthus roseus (4 variedades), Chrysanthemum morifolium (115 variedades), Celosia cristata (2 variedades), Chamaerops humilis, Coleus blumei (2 variedades), Cyclamen persicum (13 variedades), Dahlia x hybrida, Dianthus sp. (4 variedades), Dianthus chinensis x barbatus, Delphinium sp., Delphinium elatum, Eustoma grandiflorum (9 variedades), Gazania rigens (5 variedades), Gerbera jamesonii (9 variedades), Gladiolus sp. (11 variedades), Gomphrena sp., Gypsophylla sp., Helianthus sp. (4 variedades), Hemerocallis sp., Hyppeastrum sp. (2 variedades), Hypoestes phillostachia (2 variedades), I. hostii (15 variedades), K. blossfeldiana, Limmonium sp., Lilium sp. (28 variedades), Lobelia erineus (6 variedades), Lobularia maritima, Pelargonium hortorum, Pentas lanceolata (3 variedades), Petunia hybrida (6 variedades), Portulaca sp. (2 variedades), Saintpaulia ionantha (7 variedades), Salvia sp. (3 variedades), Senecio sp., Spathiphyllum sp. (3 variedades), Tagetes patula (6 variedades), Torenia fournieri, Verbena x hybrida, Viola cornuta, Viola x wittrockiana (34 variedades), Tulipa sp. (5 variedades), Zinnia elegans (9 variedades), além das orquídeas: Cattleya sp. (2 híbridos), Dendrobium sp., Oncidium sp., Phalaenopsis sp. (36 híbridos) e Vanda sp., foram analisadas. Essas amostras foram provenientes da Dinamarca, Holanda, Estados Unidos, Japão, Tailândia e Israel. Desses 50 gêneros, apenas em Phalaenopsis sp. e Lilium sp., provenientes da Holanda, foi detectada a presença de vírus.

Análises em materiais destinados à exportação-Gladiolus sp. e Hyppeastrum sp. - foram também realizadas, detectando-se, em algumas amostras, partículas alongado-flexuosas relacionadas serologicamente ao BYMV.

Um aspecto notável desse levantamento foi a identificação de espécies ornamentais como potenciais reservatórios para diferentes vírus. Assim, destaca-se E. grandiflorum como hospedeira para CMV, Tospovirus (CSNV, GRSV, TCSV e TSWV), Potyviridae, TSV e Nepovirus, e I. holstii como hospedeira para CMV, Tospovirus, Potyviridae e Tymovirus.

Com relação aos vetores, foram identificados vírus transmitidos por afídios (BYMV, CMV, Caulimovirus, DsMV), tripes (Tospovirus, TSV), coleópteros (EMV, PetVBV), nematóides (Nepovirus, PepRSV) e instrumentos de poda (CymMV, ORSV, TMV, ToMV). Entretanto, como grande parte das plantas ornamentais analisadas é vegetativamente propagada, essa pode ter sido a maneira mais eficaz de disseminação dos vírus na cultura. Desse modo, pode-se sugerir, como método de controle indireto para tais viroses, o uso de material propagativo sabidamente sadio, inspeção periódica da cultura com eliminação das plantas com sintomas e a identificação dos vírus presentes na cultura para permitir o conhecimento dos modos de transmissão desse patógeno e controle dos potenciais vetores de fitovírus.

\section{REFERÊNCIAS BIBLIOGRÁFICAS}

ALEXANDRE, M.A.V.; DUARTE, L.M.L.; RIVAS, E.B. \& CHAGAS, C.M. Mixed infection by Tospovirus in ornamental crops in São Paulo State, Brazil. Summa Phytopathologica, v.25, p.353-356, 1999.

ALEXANDRE, M.A.V.; DUARTE, L.M.L; RIVAS, E.B.; CHAGAS, C.M.; BARRADAS, M.M. \& KOENIG, R. Petunia vein banding virus: characterization of a new Tymovirus from Petunia x hybrida. Plant Disease, v.84, p.739-742, 2000a.

ALEXANDRE, M.A.V.; GALLETI, S.R.; DUARTE, L.M.L.; MIYAI, T. \& RIVAS, E.B. Bean yellow mosaic virus on gladiolus in Brazil. Virus Reviews Research, v.7: 17-21, 2002.

ALEXANDRE, M.A.V; RIVAS, E.B.; DUARTE, L.M.L. \& OKUYAMA, M.H. Serological survey of Tospovirus on Chrysanthemum sp. crops in São Paulo State, Brazil. Fitopatologia Brasileira, v.21, p.80-84, 1996.

ALEXANDRE, M.A.V.; SOARES, R.M.; RIVAS, E.B.; DUARTE, L.M.L.; CHAGAS, C.M.; SAUNAL, H.; VAN REGENMORTEL, M.H.V. \& RICHTZEINHAIN, L.J. Characterization of a strain of Tobacco mosaic virus from petunia. Journal Phytopathology, v.148, p. 601-607, $2000 \mathrm{~b}$.

BRUNT, A.; CRABTREE, K.; DALLWITZ, M.; GIBBS, A. \& WATSON, L. Viruses of plants. Descriptions and lists from VIDE database. Wallingford: CAB International, 1997. 1484p.

CHOMCZYNSKI, P. \& SACCHI, N. Single step method of RNA isolation by acid guanidium thiocianate-phenolchloroform extraction. Analytical Biochemistry, v.162, p.156-159, 1987.

COHEN, J. Alphabetical listing of viruses, viroids, and mycoplasma-like organisms infecting ornamental plants. . In: LOEBENSTEIN, G.; LAWSON, R.H. \& BRUNT, A.A. (Eds.) Virus and virus-like diseases of bulb and flower crops. Chichester: John Wiley \& Sons, 1995. p.529-534.

COSTA, A.S. Tornou-se rara a ocorrência do vírus do mosaico do pepino em plantações de alface e tomate no Estado de São Paulo. Summa Phytopathologica, v.9, p.39, 1983. 
DIJKSTRA, J. \& DE JAGER, C.P. Practical Plant Virology - Protocols and exercises. Berlin: Springer, 1998. p.348362.

DUARTE, L.M.L.; ALEXANDRE, M.A.V.; RIVAS, E.B.; MATOS, M.F. \& CHAGAS, C.M. Occurrence of Potyviridae in ornamental plants. Resumos da $5^{\text {a }}$ Virológica, Ribeirão Preto, v.6, 1995.

DUARTE, L.M.L.; FERNANDES, F.M.C.; RIVAS, E.B.; CILLI, A. \& ALEXANDRE, M.A.V. Phylogenetic analysis of Cucumber mosaic virus isolates. Virus Reviews and Research, v.8 (Supl.), p.198-199, 2003 a.

DUARTE, L.M.L.; RIVAS, E.B.; ALEXANDRE, M.A.V. \& FERRARI, J.T. Detection of CMV isolates from Commelinaceae species. Fitopatologia Brasileira, v.19, p.248-253, 1994.

DUARTE, L.M.L.; RIVAS, E.B.; ALEXANDRE, M.A.V. \& HARAKAVA, R. Serological and molecular comparison among CMV strains from ornamental plants. Virus Reviews and Research, p.155, 2001.

DUARTE, L.M.L.; SEABRA, P.V.; RIVAS, E.B.; GALLETI, S.R. \& ALEXANDRE, M.A.V. Single and double viral infection in Alstroemeria sp. Revista Brasileira de Horticultura Ornamental, v.5, p.24-33, 1999.

DUARTE, L.M.L.; SOARES, R.M.; FERNANDES, F.M.C.; ALEXANDRE, M.A.V.; TOZETTO, A R.P.; CILLI, A. \& RIVAS, E.B. Tomato mosaic virus isolado de Impatiens Hawkeri: análise filogenética molecular. Arquivos Instituto Biológico, v.70, p.136-141, 2003 b.

FRANCISCO, V.L.F.S.; PINO, F.A. \& KIYUNA, I. Floricultura no Estado de São Paulo. Informações Econômicas, v.33, p.1-16, 2003.

FREITAS, J.C. Incidência e controle de viroses em orquídeas no Estado de São Paulo. Piracicaba: ESALQ, 1996. 95p. Dissertação (Mestrado).

GIBBS, A.; ARMSTRONG, J.; MACKENZIE, A.M. \&WEILLER, G.F. The GPRIME package: computer programs for identifying the best regions of aligned genes to target in nucleic acid hybridization-based diagnosis tests, and their use with plant viruses. Journal of Virological Methods, v.74, p.67-76, 1998.

GIBBS, A. \& MACKENZIE, A.M. A primer pair for amplifying part of the genome of all potyvirids by RT-PCR. Journal of Virological Methods, v.63, p.9-16, 1997.

MALTER, A.J. The dynamic nature of the market for ornamentals: implications for virus research. Acta Horticultural, v.432, p.28-35, 1996.

NAGATA, T.; ALMEIDA, A.C.L.; RESENDE, R.O. \& ÁVILA, A.C. The identification of the vector species of Tospovirus species, Chrysanthemum stem necrosis virus and Iris yellow spot virus occurring in Brazil. Fitopatologia Brasileira, v.24, p.260, 1999.
PAVAN, M.A.; COSTA, A.S.; KUROSAWA, C.; FORTI, L.C. \& GUIMARÃES, A.M. Colonização do tomateiro e ervas daninhas pelo tripes vetor do vira-cabeça do tomateiro. Horticultura Brasileira, v.11, p.122-125, 1993.

RESENDE, R.O.; POZZER, L.; NAGATA, T.; BEZERRA, I.C.; LIMA, M.I.; BRITO GIORDANO, L.; KITAJIMA, E.W. \& ÁVILA, A.C. New tospoviruses found in Brazil. Acta Horticulturae, v.431, p.78-89, 1996.

RIVAS, E.B.; ALEXANDRE, M.A.V. \& DUARTE, L.M.L. Infecção natural de Dasheen mosaic virus em Dieffenbachia sp. Summa Phytopathologica, v.24, p.71, 1998a.

RIVAS, E.B.; KOENIG, R.; DUARTE, L.M.L.; ALEXANDRE, M.AV.; GALLETI, S.R. \& BANDETINI, E.P.T. Identificação de Eggplant mosaic virus isolado de $P e$ peromia obtusifolia. Summa Phytopathologica, v.29, p.313-316, 2003.

RIVAS, E.B.; ALEXANDRE, M.A.V. \& DUARTE, L.M.L. Doenças viróticas: aspectos fitossanitário das orquídeas. Boletim Técnico, v.11, p. 45-49, 1998 b.

RIVAS, E.B.; ALEXANDRE, M.A.V.; DUARTE, L.M.L.; SEABRA, P.V.; GALLETI, S.R. \& SOARES, R.M. Identificação de Tospovirus em plantas ornamentais. In: CONGRESSO BRASILEIRO DE FLORICULTURA E PLANTAS ORNAMENTAIS, 13, São Paulo, 2001. Resumos..., São Paulo, SBFPO, 2001. p.138.

RIVAS, E.B.; DUARTE, L.M.L.; ALEXANDRE, M.A.V.; GALLETI, S.R. Dasheen mosaic virus in Anthurium species. Virus Reviews and Research, v.2, p.192-193, 1997.

RIVAS, E.B.; DUARTE, L.M.L.; ALEXANDRE, M.A.V. \& GALLETI, S.R. Tomato chlorotic spot virus (TCSV) in Dieffenbachia and Bouvardia. Virus Reviews and Research, v.7, p.22-30, 2002.

RIVAS, E.B.; GALLETI, S.R.; DUARTE, L.M.L.; SEABRA, P.V. \& ALEXANDRE, M.A.V. Virus and phytoplasm diseases of lisianthus. Summa Phytopathologica, v.26, p.257-262, 2000.

ROOSSINCK, M.J. Evolutionary history of Cucumber mosaic virus deduced by Phylogenetic Analyses. Journal of Virology, v.76, p.3382-3387, 2002.

SILBERSCHMIDT, K. Asclepias curassavica, a natural host of Cucumber mosaic virus in Brazil. Plant Disease Reporter, v.39, p.555-557, 1955.

SHUKLA, D.D.; WARD, C.W. \& BRUNT, A.A. The Potyviridae. Wallingford: CAB International, 1994. 516p.

WIJKAMP, I.; VAN LENT, J.; KORMELINK, R.; GOLBACH, R. W. \& PETERS, D. Multiplication of Tomato spotted wilt virus in its insect vector, Frankliniella occidentalis. Journal of General Virolology, v.74, p.341-349, 1995. 